\title{
Early prostate-specific antigen response post-abiraterone as predictor of overall survival in metastatic castrate-resistant prostate cancer
}

\author{
Joshua P. Schiff' ${ }^{1}$, Patrick Cotogno ${ }^{1}$, Allison Feibus ${ }^{1}$, Peter Steinwald ${ }^{1}$, Elisa Ledet ${ }^{1}$, Brian Lewis ${ }^{1,2}$
} and Oliver Sartor ${ }^{1,2^{*}}$

\begin{abstract}
Background: Abiraterone is an important agent in the treatment of advanced prostate cancer. Early changes in prostate-specific antigen while on abiraterone in patients with metastatic castrate-resistant prostate cancer potentially have financial and health implications for patients. Limited data is available on early prostate-specific antigen change and subsequent survival given phase III trials did not measure prostate-specific antigen changes before 12 weeks.

Methods: A single-center retrospective study was performed. Metastatic castrate-resistant prostate cancer patients treated with abiraterone (without prior enzalutamide) at Tulane Cancer Center were reviewed with a focus on early prostate-specific antigen decline and relationship to overall survival.

Results: A total of 110 patients were analyzed for prostate-specific antigen response of $\geq 30$ and $\geq 50 \%$ at 4, 8, and 12 weeks. A prostate-specific antigen response of either $\geq 30 \%$ or $\geq 50 \%$ at 4,8 , or 12 weeks was associated with improved overall survival at all time points except $\geq 50 \%$ decline at 8 weeks. Multivariate analysis indicated, for all time points, that early prostate-specific antigen declines were predictive of overall survival. The neutrophil to lymphocyte ratio and docetaxel pretreatment also were predictive in many, but not all, of the multivariate analyses.

Conclusions: $A \geq 30 \%$ or $\geq 50 \%$ prostate-specific antigen decline at 4, 8 , or 12 weeks provides important information regarding subsequent overall survival for patients with metastatic castrate-resistant prostate cancer. While these data require validation with a large, multi-institutional trial, they can provide physicians with information regarding prognosis and the timing of expected outcomes. These data affirms the notion that prostatespecific antigen responses as early as 4 weeks after abiraterone initiation can be used to inform both patients and physicians about metastatic castrate-resistant prostate cancer outcomes after initiating treatment with this important but costly therapeutic choice.
\end{abstract}

Keywords: mCRPC, PSA, Abiraterone, Response, Survival

\footnotetext{
* Correspondence: osartor@tulane.edu

${ }^{1}$ Tulane Cancer Center, Tulane University School of Medicine, 1430 Tulane Ave., SL-42, New Orleans, LA 70112, USA

${ }^{2}$ Hematology-Oncology Section, Department of Medicine, Tulane University

School of Medicine, 1430 Tulane Ave., New Orleans, LA 70112, USA
}

(c) The Author(s). 2019 Open Access This article is distributed under the terms of the Creative Commons Attribution 4.0 International License (http://creativecommons.org/licenses/by/4.0/), which permits unrestricted use, distribution, and reproduction in any medium, provided you give appropriate credit to the original author(s) and the source, provide a link to the Creative Commons license, and indicate if changes were made. The Creative Commons Public Domain Dedication waiver (http://creativecommons.org/publicdomain/zero/1.0/) applies to the data made available in this article, unless otherwise stated. 


\section{Background}

Abiraterone and enzalutamide are two of the most important agents introduced in recent years for the treatment of advanced prostate cancer. Abiraterone has been approved by regulatory agencies after pivotal trials in the post-docetaxel metastatic castrate-resistant prostate cancer (mCRPC) space [1], the chemotherapy naïve mCRPC space [2], and the high-risk castrate-sensitive prostate cancer (CSPC) setting [3, 4]. Enzalutamide is approved similarly to abiraterone in the mCRPC space $[5,6]$, but it also approved in the non-metastatic CRPC (nmCRPC) space [7]. One additional hormonal agent, apalutamide, is approved for nmCRPC [8].

In the post-docetaxel CPRC studies for both abiraterone and enzalutamide, overall survival (OS) was the primary endpoint. For the chemotherapy naive mCRPC studies, radiographic progression-free survival (rPFS) and OS were co-primary endpoints for both abiraterone and enzalutamide. In all of these cited studies, prostate-specific antigens (PSAs), bone scans, and CT scans were obtained at prescribed intervals. In all the mCRPC studies, PSA testing was obtained at baseline and the first post-treatment PSA was scheduled at twelve weeks post-treatment initiation. Thus early changes in PSA were not available in the large phase III studies with either abiraterone or enzalutamide.

To examine the early changes in PSA, and how they might relate to more important outcomes such as survival, there are limited data. Early changes are potentially important for a variety of reasons, one of the most being that out of pocket costs for patients can be problematic and understanding the probability of longer term benefit is critical for some patients who need to balance the potential benefits of therapy against the costs of therapy. Cost concerns have frequently been voiced about cancer treatments. Though such issues are often discussed in the context of lesser developed countries where medical insurance rarely covers the costs of expensive therapies [9], even insured patients can be overwhelmed by the cost of cancer care [10].

One single institution study at the Royal Marsden specifically looking at early PSA response after abiraterone was published by Rescigno et al. [11]. In that retrospective study $(N=274)$, a $\geq 30 \%$ PSA decline at four weeks was associated with longer OS (25.8 vs 15.1 months; hazard ratio $(\mathrm{HR})=0.47, p<0.001)$, in both univariate and multivariate models. Facchini et al. [12] examined PSA declines fifteen days after starting abiraterone and concluded that $>50 \%$ declines in PSA were associated with OS ( $\mathrm{HR}=$ $0.21, p<0.01)$, however median OS values were not obtainable due to relative immaturity of the data.

Herein we retrospectively examine mCRPC patients treated from a single institution with abiraterone. We focus on early PSA changes predictive of OS in a mature data set. Such information can potentially be helpful to both patients and physician alike.

\section{Methods}

Patients with confirmed metastatic castrate resistant prostate cancer (mCRPC) treated with first line abiraterone between 2012 and 2018 at the Tulane Cancer Center were considered for analysis. PSA value at baseline and at four, eight, and twelve weeks were required for study inclusion. Demographics and baseline characteristics such as prior docetaxel exposure were recorded, as well as routine lab studies including PSA, albumin (Alb), alkaline phosphatase (ALP), neutrophil to lymphocyte ratio (NL ratio), and hemoglobin $(\mathrm{Hgb})$ at start of treatment, when available.

The primary investigation of interest was PSA decline as a predictor of overall PSA response and survival. PSA was procured at four, eight, and twelve. PSA response was defined as $>30 \%$ decrease from the PSA at the start of treatment. PSA responses $\geq 50 \%$ decrease from the PSA at the start of treatment were also analyzed.

Kaplan-Meier analyses were used to estimate overall survival differences between groups at each time point. Associations between PSA response and survival were evaluated via univariate Cox regression analysis for $\geq 30 \%$ and $\geq 50 \%$ response at four, eight, and twelve weeks and with multivariate Cox regression models for $\geq 30$ and $\geq 50 \%$ response at four, eight, and twelve weeks. The variables included in univariate and multivariate regression analysis included PSA responses at four, eight, and twelve weeks and baseline values for PSA, Alb, Hgb, ALP, NL ratio, and prior docetaxel use. Variables with a non-normal distribution were log-transformed (including baseline PSA, ALP, and NL ratio). The models were checked for both proportional hazards and non-collinearity. Multiple imputation was performed on the baseline covariates with missing values, which were deemed missing at random. Missing data and frequency included Alb (35.4\%), ALP (26.0\%), NL ratio (7.1\%), and Hgb (36.28\%). Ten iterations were performed and assessed to ensure procedure performance. Additionally, 100 imputations were performed to verify the initial results. Data analysis was completed via SAS/STAT ${ }^{\circledR}$ software. Correlation between various time points was assessed utilizing Spearman's rank correlation coefficients.

Table 1 Baseline characteristics

\begin{tabular}{lll}
\hline Characteristics & $\mathrm{N}$ & Median (Range) \\
\hline Total patients & 110 & \\
Age & 110 & $74.5(53-94)$ \\
Patients without prior docetaxel exposure & 67 & \\
Patients with prior docetaxel exposure & 43 & \\
Prostate-specific antigen $\mu \mathrm{g} / \mathrm{ml}$ & 110 & $42.3(2.5-3810)$ \\
Alkaline Phosphate U/I & 87 & $101(9.1-1600)$ \\
Albumin g/l & 73 & $3.8(2.5-4.8)$ \\
Hemoglobin g/l & 72 & $12.4(8.4-15)$ \\
Neutrophil to Lymphocyte Ratio & 105 & $3.6(0.7-18)$ \\
\hline
\end{tabular}




\section{Results}

In this single-institution retrospective review, 159 mCRPC patients were considered for analyses. Ultimately, 110 patients were considered for statistical review, strictly based on data availability. Three subjects were eliminated from the analysis as a result of missing baseline values. Baseline characteristics of patients are summarized in Table 1.

Spearman's rank correlation coefficients were utilized to determine correlation between PSA response at four, eight, and twelve weeks. There was a strong correlation between PSA response at four and eight weeks $($ Rho $=$

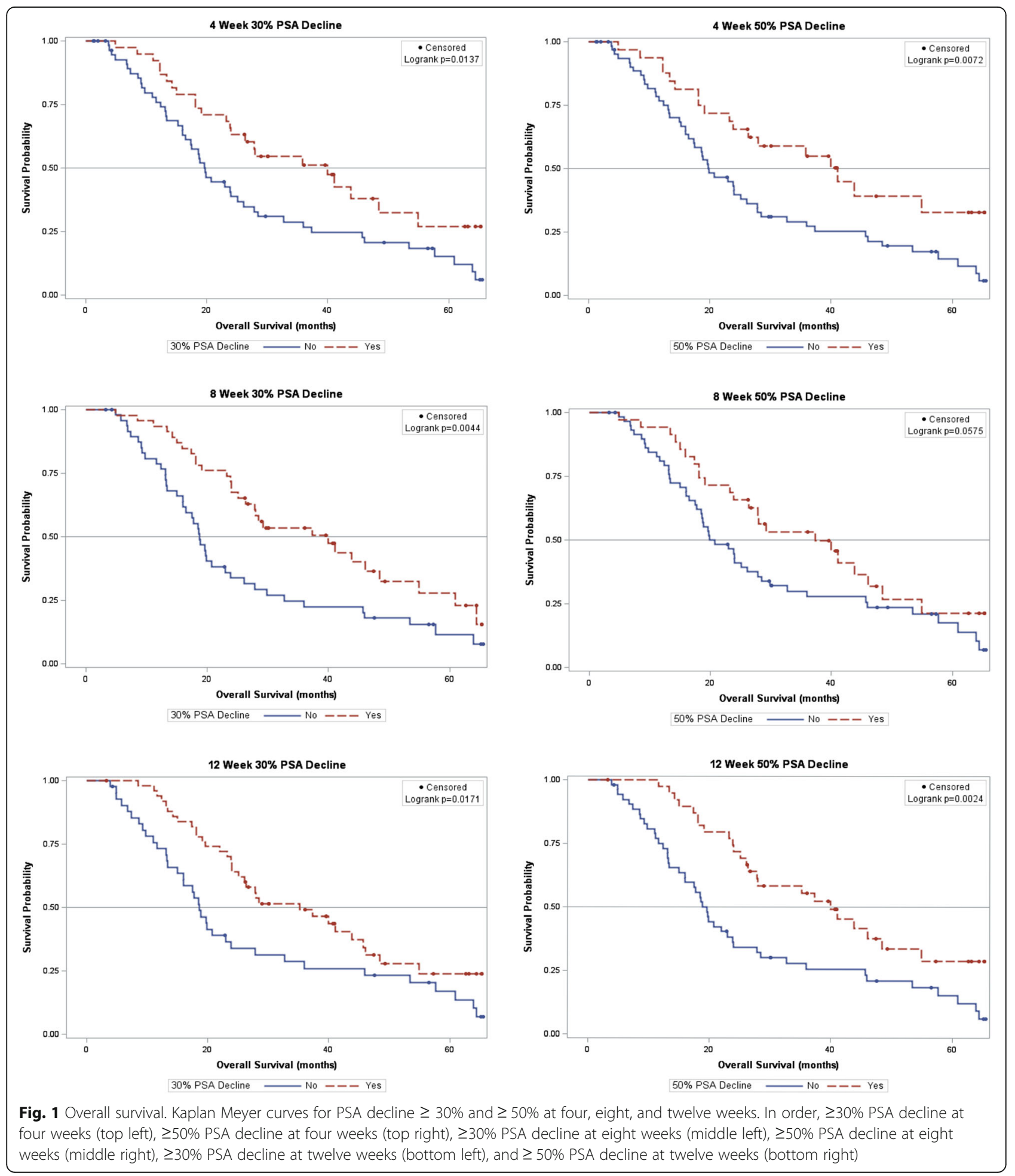


0.91, $p=<0.001)$, PSA response at four and twelve weeks (Rho $=0.75, p=<0.001$ ), and PSA response at eight and twelve weeks (Rho $=0.89, p=<0.001$ ).

A PSA response of $\geq 30 \%$ at four, eight, and twelve weeks $(\mathrm{HR}=0.54,0.51$, and 0.56 , respectively, all $p<0.05)$ was associated with improved OS as compared to subjects without such a decline (see Fig. 1 and Table 2). At four weeks the OS for patients with a PSA response $\geq 30 \%$ was significantly greater than patients without a $\geq 30 \%$ PSA response, and this was consistent at all the time points (Table 2). For those with $\mathrm{a} \geq 30 \%$ PSA response at the four, eight, and twelve week time points, OS varied from 35.2 months to 40.0 months with the longest survivals for those with the declines at four and eight weeks. For those with $a \geq 50 \%$ PSA response at the four, eight, and twelve weeks points, OS varied from 37.3 months to 41.1 months with the longest survivals for those with the declines at four weeks. Confidence intervals for OS overlapped for those with $\geq 30 \%$ or $\geq 50 \%$ declines at all the time points evaluated.

Multivariable Cox regression analysis was then utilized to determine which variables remained significant for OS taking baseline Alb, Hgb, Alp, PSA, NL ratio, prior docetaxel use and PSA declines at four weeks into account. $\mathrm{A} \geq 30 \%$ PSA response at four weeks was associated with improved OS $(\mathrm{HR}=0.51,95 \%$ CI $0.29-0.90$,
Table 2 Overall survival data

\begin{tabular}{|c|c|c|c|c|}
\hline Outcome $(n, \%)$ & Survival (months) & $p$-value & HR $(95 \% \mathrm{Cl})$ & $p$-value \\
\hline \multicolumn{5}{|c|}{$\geq 30 \%$ PSA response at 4 weeks (97) } \\
\hline Yes $(38,39.2)$ & $40.0(23.9-55.0)$ & 0.014 & $0.54(0.33-0.89)$ & 0.015 \\
\hline No $(59,60.8)$ & $19.7(16.0-25.1)$ & & & \\
\hline \multicolumn{5}{|c|}{$\geq 50 \%$ PSA response at 4 weeks (97) } \\
\hline Yes $(32,33.0)$ & 41.1 (23.2-NE) & 0.007 & $0.49(0.28-0.83)$ & 0.006 \\
\hline No $(65,67.0)$ & $19.9(16.0-26.1)$ & & & \\
\hline \multicolumn{5}{|c|}{$\geq 30 \%$ PSA response at 8 weeks (95) } \\
\hline Yes $(46,48.4)$ & $40.0(25.1-48.4)$ & 0.004 & $0.51(0.32-0.82)$ & 0.005 \\
\hline No $(49,51.6)$ & $18.7(16.0-23.9)$ & & & \\
\hline \multicolumn{5}{|c|}{$\geq 50 \%$ PSA response at 8 weeks (95) } \\
\hline Yes $(35,36.8)$ & $37.4(23.9-46.0)$ & 0.058 & $0.62(0.38-1.02)$ & 0.054 \\
\hline No $(60,63.2)$ & $20.3(17.8-26.1)$ & & & \\
\hline \multicolumn{5}{|c|}{$\geq 30 \%$ PSA response at 12 weeks (93) } \\
\hline Yes $(51,54.8)$ & $35.2(24.0-45.7)$ & 0.017 & $0.56(0.35-0.91)$ & 0.019 \\
\hline No $(42,45.2)$ & $18.6(13.4-23.9)$ & & & \\
\hline \multicolumn{5}{|c|}{$\geq 50 \%$ PSA response at 12 weeks (93) } \\
\hline Yes $(40,43.0)$ & $40.0(26.1-55.0)$ & 0.002 & $0.47(0.29-0.77)$ & 0.002 \\
\hline No $(54,57.0)$ & $19.6(15.0-23.9)$ & & & \\
\hline
\end{tabular}

Data from Kaplan Meyer and univariate cox regression analyses for a PSA response $\geq 30 \%$ and $\geq 50 \%$ at four, eight, and twelve weeks. Median survival is presented in months $(95 \% \mathrm{Cl})$. NE = not evaluable. $P$-values in bold text are statistically significant $(p \leq 0.05)$

Table $\mathbf{3}$ Cox multivariate regression analysis

\begin{tabular}{|c|c|c|c|}
\hline Time Point & Variable & $\mathrm{HR}(95 \% \mathrm{Cl})$ & $p$-value \\
\hline \multirow[t]{7}{*}{4 Weeks $(n=93)$} & $\geq 30 \%$ PSA response at 4 weeks & $0.51(0.29-0.90)$ & 0.021 \\
\hline & Alb & $0.99(0.51-1.94)$ & 0.978 \\
\hline & $\mathrm{Hgb}$ & $0.90(0.73-1.10)$ & 0.306 \\
\hline & ALP & $1.47(0.91-2.35)$ & 0.112 \\
\hline & PSA & $1.13(0.93-1.37)$ & 0.205 \\
\hline & NL Ratio & $1.72(1.13-2.62)$ & 0.012 \\
\hline & Prior docetaxel use & $0.47(0.27-0.80)$ & 0.005 \\
\hline \multirow[t]{7}{*}{8 Weeks $(n=92)$} & $\geq 30 \%$ PSA response at 8 weeks & $0.40(0.24-0.69)$ & 0.001 \\
\hline & Alb & $1.14(0.56-2.30)$ & 0.716 \\
\hline & $\mathrm{Hgb}$ & $0.96(0.80-1.15)$ & 0.645 \\
\hline & ALP & $1.50(0.95-2.34)$ & 0.079 \\
\hline & PSA & $1.30(1.07-1.58)$ & 0.010 \\
\hline & NL Ratio & $1.80(1.20-2.70)$ & 0.005 \\
\hline & Prior docetaxel use & $0.75(0.44-1.28)$ & 0.285 \\
\hline \multirow[t]{7}{*}{12 Weeks $(n=91)$} & $\geq 30 \%$ PSA response at 12 weeks & $0.48(0.27-0.83)$ & 0.009 \\
\hline & Alb & $0.94(0.50-1.78)$ & 0.849 \\
\hline & $\mathrm{Hgb}$ & $0.94(0.78-1.13)$ & 0.499 \\
\hline & ALP & $1.46(0.90-2.37)$ & 0.122 \\
\hline & PSA & $1.19(1.00-1.44)$ & 0.083 \\
\hline & NL Ratio & $1.87(1.22-2.87)$ & 0.004 \\
\hline & Prior docetaxel use & $0.65(0.38-1.10)$ & 0.108 \\
\hline
\end{tabular}


$p=0.021$ ) (Table 3). In addition baseline NL ratio and prior docetaxel use were also significant. Cox multivariate regression analysis was additionally performed for $a \geq 30 \%$ PSA response at eight and twelve weeks, with both being associated with a statistically significant increase in rate of survival. For the $\geq 30 \%$ PSA decline at eight weeks $\mathrm{HR}=0.40,95 \% \mathrm{CI} 0.24-0.69, p=0.001$, and at twelve weeks, $\mathrm{HR}=0.48,95 \% \mathrm{CI} 0.27-0.83, p=0.009$. Assessments of additional variables in the multivariate analyses for eight and twelve weeks were similar except that prior docetaxel was not a significant predictor of OS at eight or twelve weeks. We also performed (not shown) Cox multivariable regression analyses at all time points for $\geq 50 \%$ PSA decline. Consistent significance was found for the $\geq 50 \%$ PSA declines at all time points examined ( $p=0.019, p=0.032$, and $p=0.002$ at four, eight, and twelve weeks). Baseline NL ratio was also significant at all the time points. Baseline PSA and prior docetaxel were inconsistently significant. Post-abiraterone treatment data was not fully accessible due to referral patterns.

\section{Discussion}

Our data confirms the previous findings of the prior Rescigno et al. [11] retrospective study at the Royal Marsden showing the importance of four week PSA changes in predicting OS. Unlike the Rescigno et al. study, this study evaluated $\geq 30 \%$ and $\geq 50 \%$ PSA response evaluated as a predictor of OS overall survival at all early time points (four, eight, and twelve weeks). Though there were minor differences in HR and statistical significance, all confidence intervals overlapped and these data do not support meaningful differences between $30 \%$ or $50 \%$ PSA declines at four, eight, and twelve weeks when predicting eventual OS.

NL ratio has previously been shown to have an impact on PSA response and OS after abiraterone [13] and our analyses indicate that the OS is influenced by this variable as well. Thus our NL ratio data are consistent with prior literature.

Based on these data, the recommendation to the physician is not to stop treatment at four weeks. However, these data can provide both the treating physician and the patient with critical information with regards to prognosis. One can utilize this platform to establish prognosis, to a statistically significant degree, by a simple-metric that is easily measured. Furthermore, it is critical to mention that the decision to withdraw or continue treatment cannot be solely based on this metric, but that other factors such as cost, quality of life, and insurance coverage, amongst others, must be incorporated into the clinical action plan.

This study has a number of limitations. This was a single-institution retrospective study, and therefore the results are potentially biased in both location and time.
There is certainly a need to validate these findings with independent, multi-institutional datasets. Furthermore, not all abiraterone treated patients were included as variables necessary for these analyses were sometimes missing. Furthermore, multiple imputation was utilized to complete the datasets for the multivariate analyses. Some of the variables of known prognostic importance such as ECOG performance status and LDH were not complete in this dataset and analyses including these variables were not performed.

\section{Conclusions}

These data suggest that clinicians and patients alike can utilize early PSA response criteria to inform the probability of subsequent events. These types of data are lacking when viewing the large phase III trials in MCRPC with abiraterone [1-4], which delayed assessment of PSA until twelve weeks after starting therapy. Though the difference between four and twelve weeks may seem minor, the cost of abiraterone for eight weeks might exceed $\$ 16,000$, which is a substantial. Using these data, and the PSA data from the Royal Marsden at four weeks, patients can be better informed of their prognosis after only four weeks of abiraterone exposure and be better empowered to make decisions regarding their health care expenditures.

\section{Abbreviations}

Alb: Albumin; ALP: Alkaline phosphatase; CSPC: Castrate-sensitive prostate cancer; Hgb: Hemoglobin; HR: Hazard ratio; mCRPC: Metastatic castrateresistant prostate cancer; NL ratio: Neutrophil to lymphocyte ratio; nmCRPC: non-metastatic castrate-resistant prostate cancer; OS: Overall survival; PSA: Prostate-specific antigen; rPFS: Radiographic progression-free survival

\section{Acknowledgements}

This study was conducted at the Tulane Cancer Center under the guidance and supervision of the Tulane University School of Medicine including the Hematology-Oncology Section of the Department of Medicine.

\section{Funding \\ Not applicable.}

\section{Availability of data and materials}

The datasets used and/or analyzed during the current study are available from the corresponding author on reasonable request.

\section{Authors' contributions \\ JS collected, analyzed and interpreted the data as well as was a major contributor in writing the manuscript. PC provided the majority of statistical analysis as well as provided the figures and tables for the manuscript. AF collected a large amount of data for the dataset. PS collected a large amount of data for the dataset. EL provided guidance in analyzing the dataset and contributed to writing the manuscript. BL provided guidance in analyzing the manuscript and assisted in data collection. OS oversaw the analysis of the dataset, provided guidance in creating the dataset and manuscript, and was a major contributor in writing the manuscript. All authors read and approved the final manuscript.}

\section{Ethics approval and consent to participate}

This research is strictly retrospective and involving the collection of existing data and records and therefore the need for informed consent was waived by the Institutional Review Board of Tulane University. This study was approved by the Institutional Review Board of Tulane University (IRB 604170-10). 


\section{Consent for publication}

Not applicable.

\section{Competing interests}

Dr. Oliver Sartor discloses that he receives compensation as a consultant for Janssen, Medivation, Pfizer, and Sanofi. Joshua Schiff, Patrick Cotogno, Allison Feibus, Peter Steinwald, Elisa Ledet, and Dr. Brian Lewis declare no potential conflicts of interest.

\section{Publisher's Note}

Springer Nature remains neutral with regard to jurisdictional claims in published maps and institutional affiliations.

Received: 26 September 2018 Accepted: 17 May 2019

Published online: 31 May 2019

\section{References}

1. de Bono JS, Logothetis CJ, Molina A, Fizazi K, North S, Chu L, et al. Abiraterone and increased survival in metastatic prostate cancer. N Engl J Med. 2011;364:1995-2005.

2. Ryan CJ, Smith MR, de Bono JS, Molina A, Logothetis CJ, de Souza P, et al. Abiraterone in metastatic prostate cancer without previous chemotherapy. N Engl J Med. 2013;368:138-48

3. James ND, de Bono JS, Spears MR, Clarke NW, Mason MD, Dearnaley DP, et al. Abiraterone for prostate cancer not previously treated with hormone therapy. N Engl J Med. 2017:377:338-51.

4. Fizazi K, Tran N, Fein L, Matsubara N, Rodriguez-Antolin A, Alekseev BY, et al. Abiraterone plus prednisone in metastatic, castration-sensitive prostate cancer. N Engl J Med. 2017;377:352-60.

5. Beer TM, Armstrong AJ, Rathkopf DE, Loriot Y, Sternberg CN, Higano CS, et al. Enzalutamide in metastatic prostate cancer before chemotherapy. N Engl J Med. 2014;371:424-33.

6. Scher HI, Fizazi K, Saad F, Taplin ME, Sternberg CN, Miller K, et al. Increased survival with enzalutamide in prostate cancer after chemotherapy. $\mathrm{N}$ Engl J Med. 2012;367:1187-97.

7. Hussain M, Fizazi K, Saad F, Rathenborg P, Shore N, Ferreira U, et al. Enzalutamide in men with nonmetastatic, castration-resistant prostate cancer. N Engl J Med. 2018;378:2465-74.

8. Smith MR, Saad F, Chowdhury S, Oudard S, Hadaschik BA, Graff JN, et al. Apalutamide treatment and metastasis-free survival in prostate cancer. N Engl J Med. 2018;378:1408-18.

9. Sharma V, Kerr SH, Kawar Z, Kerr DJ. Challenges of cancer control in developing countries: current status and future perspective. Future Oncol. 2011;7:1213-22.

10. Weintraub A. Even insured patients are overwhelmed by the cost of cancer care (internet). Forbes magazine. 2017. https://www.forbes.com/sites/ arleneweintraub/2017/08/10/even-insured-patients-are-overwhelmed-bythe-cost-of-cancer-care/\#792354fb51c4. Accessed 10 Sep 2018.

11. Rescigno P, Lorente D, Bianchini D, Ferraldeschi R, Kolinsky MP, Sideris S, et al. Prostate-specific antigen decline after 4 weeks of treatment with abiraterone acetate and overall survival in patients with metastatic castration-resistant prostate cancer. Eur Urol. 2016;70:724-31.

12. Facchini G, Caffo O, Ortega C, D'Aniello C, Di Napoli M, Cecere SC, et al. Very early PSA response to abiraterone in $\mathrm{MCRPC}$ patients: a novel prognostic factor predicting overall survival. Front Pharmacol. 2016;7:123.

13. Leibowitz-Amit R, Templeton AJ, Omlin A, Pezaro C, Atenafu EG, Keizman D, et al. Clinical variables associated with PSA response to abiraterone acetate in patients with metastatic castration-resistant prostate cancer. Ann Oncol. 2014;25:657-62

Ready to submit your research? Choose BMC and benefit from:

- fast, convenient online submission

- thorough peer review by experienced researchers in your field

- rapid publication on acceptance

- support for research data, including large and complex data types

- gold Open Access which fosters wider collaboration and increased citations

- maximum visibility for your research: over $100 \mathrm{M}$ website views per year

At $\mathrm{BMC}$, research is always in progress.

Learn more biomedcentral.com/submissions 